\title{
Lawyers come from Mars, and economists come from Venus - or is it the other way round? Some thoughts on expert economic evidence in competition cases
}

\author{
Sir Marcus Smith*
}

\begin{abstract}
The deployment of complex expert economic evidence is a common feature of competition litigation. However, fundamental differences in thinking between lawyers and economists may have a bearing on the content and presentation of that evidence. This article considers the respective roles of lawyers and economists in competition litigation in the High Court and the Competition Appeal Tribunal, and how those roles interlink in practice.
\end{abstract}

Keywords: economics, competition litigation, expert evidence

\section{Introduction: recognizing differences in approach}

There is a well-known book called Men are from Mars, Women are from Venus. ${ }^{1}$ The underlying thesis of the book is that men and women come from different planets and that - if only they realised it - life would be better and easier. I am certainly not intending to venture into this area, but the title of the book made me think that there may be something in the quality - I mean the nature of legal thought that is fundamentally different to that of the thinking of an economist. My sense is that, unless this difference is recognized and articulated, courts will not make the greatest use of the economists appearing before them, and, conversely, economists will not know exactly what is expected of them.

Fundamental differences in thinking crop up in other disciplines. I recall litigating an extremely large 'tracing' claim, where one party was seeking to identify and reclaim money that it said had been stolen from it, using the (very complex) English law rules of following and tracing. One of the forensic accountants on my team - a real fan of doubleentry bookkeeping - simply could not grasp the notion of the taking of money. Surely, he said, any 'stolen' money would result in a contra-entry in the accounts reflecting the thief s obligation to repay. Unsurprisingly, we never agreed on this point, which seemed to me to amount to a reversal of Proudhon's famous statement. Proudhon said that property is theft: my forensic accountant thought theft was property! ${ }^{2}$ More seriously, this was a stark example of the difference in mindset that different disciplines can impose on the persons who profess a certain expertise. In a real sense, it is a hallmark of their expertise.

This article is concerned with the relationship between law and economics - or, perhaps more accurately, the relationship between lawyers and economists - in competition litigation. Economic evidence, as we all know, has a peculiar importance in competition cases, and so the question is a significant one.

\section{Lawyers, judges and economics}

It is necessary for me, as a lawyer and judge who has tried a fair number of competition cases, to begin by casting the plank out of my own eye, before turning to the motes in other people's eyes.

Not every competition case involves statistical analysis and complex economic thinking. But some do. Clearly, we need advocates and judges who are
A Justice of the High Court sitting in the Chancery Division and a Chairman of the United Kingdom Competition Appeal Tribunal. This is the published version of a talk given at the 10th Annual GCR Competition Litigation Conference, London, 4 October 2018. All views expressed are entirely personal.
1 J. Gray, Men are from Mars, Women are from Venus (HarperCollins, 1992).

2 'La propriété, c'est le vol!' was a slogan coined by French anarchist PierreJoseph Proudhon in his 1840 book. See P.-J. Proudhon, What is Property? Or, an Inquiry into the Principle of Right and of Government (1840). 
sufficiently well-versed in this discipline, so that they do not run a mile when presented with an equation.

In general terms, the process of deploying complex (economic) evidence works extremely well in English courts. It is appropriate that I note, at this point, that the economists who appear - either as witnesses or advisers - in competition litigation are of a very high calibre. That is the essential starting point, for it is the experts who have to be capable of educating the very competent legal teams that appear in the English High Court and the Competition Appeal Tribunal. It is these legal teams who assume the primary burden of explaining things to the judge. There may well be expert evidence in due course, but it is the lawyers who draft the pleadings and the written openings. It is the lawyers who open the case to the judge. They are the interface through which the economics is - at least initially - conveyed to the court.

The art of the advocate in such cases is just that: to act as an interface, to translate the very complex into something the intelligent layperson can understand.

However, I do think it is incumbent upon the judge perhaps with a little prompting from the advocates - to identify areas where he or she feels uncomfortable. On day 3 of the BritNed ${ }^{3}$ trial - after opening submissions, but before the hearing of evidence - we had what came to be known as a 'teach in'. Both experts were asked to explain their own methodology, in neutral terms. Both the advocates and the judge could ask questions, but only neutral or clarificatory (not point-scoring) questions. Day 3 was - certainly from my point of view, but I think for everyone - time very well spent. I should say that a 'teach in' is not a new idea, although it may be the first time it has been deployed in competition litigation. It is a tool quite often used in patent litigation.

One of the dangers of our adversarial process is that the legal teams focus so much on the controversial that they forget that the common ground, on which the controversial is perhaps built, is left unexpressed. An expert may very well take for granted and leave unexpressed the assumptions and basic principles that he or she used when communicating with the other expert. There will be, amongst experts of a common discipline, a bedrock of common understanding, common terminology and common core precepts.

'All professions', said George Bernard Shaw, 'are conspiracies against the laity. ${ }^{4}$ Unfair comment, I have to say. But there is a deeper truth: the fact that professionals

BritNed Development Ltd. v. ABB AB [2018] EWHC 2616 (Ch) ('BritNed'). G.B. Shaw, The Doctor's Dilemma (1906).

Per MacKinnon LJ in Southern Foundries (1926) Ltd v. Shirlaw [1939] 2 KB 206 at 227 : 'For my part, I think that there is a test that may be at least as useful as such generalities. If I may quote from an essay which I wrote some years ago, I then said: "Prima facie that which in any contract is left to be have these common understandings, by virtue of their profession, does have an exclusionary element. The layperson does not have these common understandings. They are not inherent to the layperson's way of thinking. And, so, they need to be spelt out.

Experts can be relied upon to articulate their thinking very clearly when the other expert disagrees. It is when the proposition is uncontroversial as between the experts that there is a danger that the proposition will be unarticulated. Every economist will accept that correlation does not equate to causation. The layperson, rightly or wrongly, may see a link between correlation and causation, and that may be right in a particular case. But correlation and causation are not the same thing, and the difference needs to be articulated particularly because the economist will say 'oh, of course'.

We lawyers all know the test for implied terms: the stranger, the officious bystander, listening in on the contracting parties, and saying 'you have not accounted for $\mathrm{X}$ ', being put-down by the parties saying testily 'but, of course, the answer is $\mathrm{Y}$, and is so clear it does not need to be articulated'. ${ }^{5}$ I wonder whether we ought not to have an 'officious expert', listening in on the parties' experts as they discuss the case, primed to say 'you have not explained this obvious point'. Instead of being told by the party-instructed experts testily to hold his or her counsel, the officious expert would be lauded. 'Thank you', the party-instructed experts would say, 'the judge may not know this...'.

\section{Educated experts}

Having cast the plank out of my own eye, let me move on to my second point, which relates to the experts and their inter-relationship with the court. We need $e d u$ cated experts.

Clearly, in saying this, I do not mean educated in economics or statistical thinking. I take that expertise as a given; and in my experience I am entirely justified in doing so. By an 'educated' expert, I mean someone with a clear understanding of what giving expert evidence in court actually entails.

Every expert in every case requiring expert reports will have an expert declaration shoved under his or her nose. Experts will be told that their duty is to the court and not to the party instructing them. This is important. The principles laid down in The Ikarian

implied and need not be expressed is something so obvious that it goes without saying; so that, if, while the parties were making their bargain, an officious bystander were to suggest some express provision for it in their agreement, they would testily suppress him with a common 'Oh, of course!"'. 
Reefer by Cresswell J and now embodied in the Civil Procedure Rules ('CPR') are most important. ${ }^{6}$ But they are also very abstract. My feeling is that - particularly as regards expert economists - the lawyers need to spell out the nature of the economist's role and what the evidence the economist is giving is seeking to achieve.

I need to be clear about what I mean by this. There are, I think, two points (and there may be more).

First: beware the unarticulated assumption. I have dealt with this already.

Second: remember that all experts operate at one remove. That is almost the definition of expert, opinion, evidence. Experts give an opinion based on the facts of the case. Facts are - as every litigator will tell you - a moveable feast. You have your witness statements from your witnesses of fact, but how a particular witness responds to cross-examination in his or her oral evidence at trial can change the entire complexion of a case. If that happens, necessarily, the opinion evidence will change also. One is based on the other.

This dichotomy between fact and opinion is straightforward for experts in fields apart from economics. The orthopaedic surgeon, called to opine on whether a hip operation was negligently performed, will obviously look at the claimant patient and the defendant doctor's notes. The expert will reach a view and will write a report setting out his or her opinion, based on these facts. He or she will obviously have to shift opinion in light of the oral evidence of the patient and that of the medical staff, should that evidence materially change, as it very well may.

But the evidence on which our hypothetical orthopaedic surgeon bases his or her opinion is clear-cut and in no way selected by the expert. The fact situation on which the surgeon must opine is imposed on him or her. There is a clear demarcation between fact and opinion.

Things are much harder for the economist. It is worth trying to understand why this is the case. Again, there are two issues:

1. The collation of evidence. Usually, the economist will be commenting on a counterfactual situation arising in a particular commercial or industrial environment, whether that be bus services in Cardiff, 7 credit and debit card payment systems and their interchange fees, ${ }^{8}$ or undersea cables. ${ }^{9}$ Very often - before even expressing an opinion - the expert economist

$6 \quad$ The Ikarian Reefer [1993] 2 Lloyd's Rep 68; CPR Part 35.

7 As in the Cardiff Bus case: 2 Travel Group plc (in liquidation) v. Cardiff City Transport Services Ltd. [2012] CAT 19.

8 The various Visa and MasterCard interchange fee cases.

9 BritNed (fn 3).

10 I should say that I see nothing wrong in this: indeed, provided each party has its own expert, and there is not a single, court-appointed expert, the will have a collating function. By that I mean a role in identifying the facts and figures that will go to form the bedrock of the expert's opinion. The expert economist, most times, has a role in furnishing an expert opinion, but also a role in collating the factual material on which that expert opinion is based. The problem is that the very process of selecting this evidence is subjective. The evidence does not select itself, and is not imposed on the expert in this case. It is chosen, and chosen by the expert. ${ }^{10}$ And because different evidence is selected and relied upon, the opinion evidence of the experts diverges. Indeed, what is probably going on is that the experts have an a priori view of what, in their judgment, is the correct analytical approach that will underpin their opinion, and it is this that informs the facts they choose to select.

2. What, exactly, is 'evidence'? There is a tendency - and I think it is a very dangerous one - to treat anything that the economist picks up, by way of knowledge, as 'evidence'.

Let me try to unpack these two points a little further.

\subsection{The collation of evidence}

As I have described, experts will very often be involved in the collation of evidence on which their reports will ultimately be based. Often, the evidence an expert economist feels that he or she needs to see will be articulated as a requirement for the production of documents from the other side during the disclosure process. In BritNed, for example, Rose J heard a contested application regarding disclosure of information relating to projects other than the BritNed interconnector (the undersea cable that $\mathrm{ABB}$ sold to BritNed, which was the subject of the claim). Both experts wanted to look at certain sets or classes of project apart from the BritNed interconnector. Of course, ABB's expert had access to this material: as the defendant supplier, ABB had this material in any event. But BritNed's expert did not. That is one reason - not the only one why the disclosure process can be so useful.

The disclosure process, and the arguments that arise about the proper ambit of disclosure in a given case, is actually a very good way of forcing the experts instructed in a case to think about what they need to see. Each expert's methodology is flushed out during the course of disclosure.

system works very well. Each party advances a theory before the court, and that theory is tested during the course of the trial. In particular, each expert will be cross-examined. As I noted in one of the BritNed consequential hearings ([2018] EWHC $3142(\mathrm{Ch})$ at [12(3)] and [23]), I found the process invaluable. 
In competition cases, it might be better to have a hearing specifically directed to the experts' articulation of their intended process of evaluation. In other words, the experts articulate why they are looking at - or want to look at certain evidence. That would require the expert - at a fairly early stage - to explain his or her 'theory of harm' or operational thesis. A hearing like this would flush out differences in approach - the subjectivities, as it were - and would force the parties to consider, at a fairly early stage, how the facts in issue (defined, in this case, by the methodologies of the experts) are going to be established.

Clearly, for this process to work, it is important to docket the case to a specific judge so that the process is controlled, from beginning to end, by a single person. BritNed, I should say, was docketed to me, but only well after disclosure. The Competition Appeal Tribunal could provide a suitable venue in this regard.

\subsection{What is evidence?}

So much for the collation of evidence. My second point runs the great risk of becoming excessively philosophical. It turns on the question of 'what is evidence?' I shall attempt to eschew the philosophical and focus on the practical.

Generally speaking, the approach of our civil and commercial courts to evidence is pragmatic and sensible. We abandon - or at least do not give pre-eminence to technical rules of evidence, which govern what evidence may and what evidence may not be admitted. Instead, we let the judge see and consider just about anything that the parties consider relevant.

Thus, submissions are directed not to technical legal questions relating to the admissibility of evidence, but why greater weight should be attached to certain evidence (in contrast to other evidence). On the whole, this is an approach that works very well.

However, for the expert economist, this is - or can be a dangerous situation. This is because of the subjective way in which the evidence that our expert will be relying upon is selected. Almost without exception, the expert reports of economists that I have seen deployed in competition litigation mix opinion with assertions of (contested) fact. For instance, assertions will be made about how the industry in question operates. Or statements will be made about historic trends in interest rates or inflation. Under our procedure, this evidence all goes in. 'Don't worry', we say, 'it's admissible, but subject to weight...'.
It is fine for the experts to reach divergent opinions on the same agreed facts. It is not fine for the experts - in their reports - to adduce evidence (as opposed to referring to evidence adduced by a witness of fact) that is controversial. That, in my judgment, involves a basic confusion as to why the expert is giving evidence.

I am beginning to think that, for competition cases, a strict evidential approach needs to be taken, so as to make everyone appreciate (and I include the judge in this) that fact is different from expert opinion.

I am thinking of the sort of formality required by Civil Evidence Act notices for hearsay statements. It seems to me that if an expert is proposing to rely on, let us say, historic inflation rates, before getting into a debate about how this data affects the expert's opinion, we first need to ask whether this material is admissible as evidence at all. I say this not to create additional work, but because I fear we have lost sight of this critical distinction between fact and opinion.

In short, we need to ensure that disputes on the facts are: first, distinct from disputes on opinion; and, second, identified early enough to enable these disputes to be aired and identified - if not resolved - well before the expert reports are exchanged. Of course, I am not saying that all such factual issues can be resolved before the trial. That is unlikely to be possible. But the issue needs, at the very least, to be identified and framed, so that it is clear before the experts give their opinions that they may need to consider, when rendering those opinions, alternative factual cases.

That is particularly true of material relating to how an industry operates. It is at a fundamental level wrong for an expert to give evidence in relation to an industry in respect of which that expert has no specific expertise. That is a point that has been made in the case law. ${ }^{11}$

This can give rise to a further problem. There will often be an information imbalance between a claimant in a competition case and the defendant(s). In a cartel case, there will be an imbalance of information not merely about how the cartel operated, but how the industry in which the cartel operated was affected, with the cartelist defendant knowing far more than the claimant. And it may be very difficult to obtain either the factual or the expert evidence in relation to how the market operated. It was evident (and entirely unsurprising) in the MasterCard and Visa litigation that one side knew far more than the other about the way in which card payment systems worked and had been developed. 
Clearly, disclosure can help a great deal in resolving such issues. But documentary evidence is not the be-all and end-all. It may be that the key factual witnesses on the defendant's side can be made available to a claimant. I have never, either as counsel or as judge, seen the deployment in a civil claim of CPR Part 34.8 (giving evidence before trial by deposition). But the power exists; and perhaps the use of that provision is something we ought to think about as a tool in competition cases.

\subsection{Taking stock}

So far, it seems to me, the mismatch between lawyers and economists really arises out of a failure of communication and understanding. Such failures can be addressed, and we have a very good infrastructure, in this jurisdiction, in which to do so. We are very lucky in the world-class economists, experts and lawyers that appear in the Competition Appeal Tribunal and the High Court.

The growing use of statistical evidence - not just in competition cases, but elsewhere also - does mean the existence of a growing cadre of judges who, when they hear of regression analyses or confidence intervals, do not shrink in terror but stare such material boldly in the face, and deal with it. And I would back the advocates - largely London-based - who appear in competition cases to grasp and be able to cross-examine on the most recondite and difficult of statistical and economic topics. If nothing else, the BritNed trial showed that.

Equally, the need to recognize and deal with what I would suggest is a very important distinction between factual evidence and opinion evidence is something that can be addressed over time.

However, I am going to suggest that whilst communication failure may be an aspect of the problem, there is something more fundamental at work here, also, in terms of the different ways economists and lawyers see the world.

\section{A different world view?}

In Hotson v. East Berkshire Area Health Authority, ${ }^{12}$ Lord Mackay discussed the use of statistics as an aid to proof of causation. In the course of his opinion, he referred to the Washington case of Herskovits v. Group Health Cooperative of Puget Sound. ${ }^{13}$ This Washington case contains a dissenting judgment of Justice Brachtenbach, who considered the following mind game. Suppose you were knocked down by an unknown taxi cab in a town with only two cab companies. Could a judge properly conclude that - all other things being equal - it was more probable than not that you had been knocked down by the cab company with the larger fleet?

It is worth quoting from Lord Mackay's speech in Hotson: ${ }^{14}$

[Justice Brachtenbach] warned against the danger of using statistics as a basis on which to prove proximate cause and indicated that it was necessary at the minimum to produce evidence connecting the statistics to the facts of the case. He gave an interesting illustration of a town in which there were only two cab companies, one with three blue cabs and the other with one yellow cab. If a person was knocked down by a cab whose colour had not been observed it would be wrong to suggest that there was a 75 per cent. chance that the victim was run down by a blue cab and that accordingly it was more probable than not that the cab that ran him down was blue and therefore that the company running the blue cabs would be responsible for negligence in the running down. He pointed out that before any inference that it was a blue cab would be appropriate further facts would be required as, for example, that a blue cab had been seen in the immediate vicinity at the time of the accident or that a blue cab had been found with a large dent in the very part of the cab which had struck the victim.

My feeling is that lawyers will agree with Justice Brachtenbach and Lord Mackay, but I wonder if economists and statisticians do?

One of the frequent questions crossing the judge's desk is causation. Did the defendant's wrongful act $A$ cause the claimant's harm $B$ ? That is a question that has to be proved on the balance of probabilities. So why are probabilities in this hypothetical example not enough? Why is it the case that this $75 \%$ chance is not enough? Would the lawyer's answer be different if the number of cabs were different? 300,000 blue cabs (all owned by a single undertaking) versus a single yellow one (owned by a one-person firm)? My feeling is that at this point the lawyer would start to feel uncomfortable about denying attribution of liability to a blue cab.

Let me give another example. The European Commission's Practical Guide on Quantifying Harm in Competition Cases provides an excellent description of how regression analysis can be used to provide an estimate of an overcharge. ${ }^{15}$ Such estimates are often provided as a point estimate, identifying the most probable point on the distribution curve. So, an expert may say, 'My model predicts an overcharge of $€ 10$.
12 Hotson v. East Berkshire Area Health Authority [1987] AC 750 ('Hotson').

13 Herskovits v. Group Health Cooperative of Puget Sound (1983) 664 P.2d 474.

14 Hotson (fn 12), p. 789.
15 European Commission Staff Working Document, Practical Guide: Quantifying Harm in Actions for Damages Based on Breaches of Article 101 or 102 of the Treaty on the Functioning of the European Union SWD(2013) 205 (11 June 2013) ('Practical Guide'). 
The problem is that this is just the most probable point on the distribution curve. The uncertainty may be considerable. The Practical Guide says this: ${ }^{16}$

One way to deal with the uncertainty of the estimate is to indicate the results not as a point estimate ('the price in the non-infringement scenario is $10 €^{\prime}$ ), but as an interval ('the price in the noninfringement scenario is between $9 €$ and $\left.11 €^{\prime}\right)$. The notion of 'confidence interval' - which is standard in statistics - is used to describe how likely it is that the true value is contained in an interval. By convention in economics, a 95\% likelihood that a specific interval does in fact contain the true value is regarded as a high degree of certainty.

But why can one not take a confidence interval of $51 \%$ (i.e. $51 \%$ of the time, the true value will fall within a range of $€ 5$ to $€ 10$ ), and then use the lowest end of that range ( $€ 5$ in this example) to represent the minimum overcharge, established on a balance of probabilities? After all, $51 \%$ of cases will, statistically speaking, have to be above €5. This - and I stress I am speaking somewhat unscientifically - seems to have an instinctive attraction to the lawyer but would strike the economist or statistician as entirely specious, even heretical. Economists and statisticians can, to an extent, rest easy, because this approach was rejected in BritNed. ${ }^{17}$

But that does not hide the fact that these are difficult questions, involving the interchange between economic and legal thinking. I suspect that the answer to these questions lies in something that every economist (or, at least, every econometrist) knows. Correlation - variable $A$ tracking variable $B$ - does not necessarily imply causation, but may simply be coincidence. Of course, the greater the correlation, the easier it may be to infer causation. If that is right, then perhaps the answer is this. It is a mistake to see economic evidence as containing 'The Answer' to, for example, a legal question of causation. Rather, it is evidence - granted of a somewhat idiosyncratic nature, at least to the lawyer - that goes into the pot with all the other evidence, on which the parties make their submissions and which the judge has to weigh.

In other words, lawyers need to look at the economic evidence, understand it for what it is, and apply it as a part of the material before the court. If that is so, then it may well be right to say that lawyers and economists do inhabit different planets. But it is up to the lawyers who present and decide these cases - to take the lead in ensuring that what is needed to resolve cases in our legal system is clearly articulated to those whose very important function it is to provide the expert opinion evidence within that system. 